\title{
EDITORIAL
}

\section{The role of people and organisations in learning technology practice}

This issue of Research in Learning Technology reflects the importance of people and organisations in the effective application of learning technology. Our journal aims (amongst other goals) to spread good practice in the use of learning technology, and the papers in this issue can help to achieve this aim. Creating an issue is as much about happenstance as planning but it is always interesting to see what the assembled papers have in common. In this collection of papers, there is a strong practice theme emerging.

In the previous issue (vol. 19, no. 1), my co-editor Rhona Sharpe wrote about the nature of evaluative evidence that we need and can produce. In the special issue on the Transformational Impact of Learning Technology (vol. 18, no. 3), the editors considered issues of strategy, implementation and integration of learning technologies in organisations. The present issue (vol. 19, no. 2) builds on these by providing further evidence of attitudes, perceptions and behaviours of staff and students that can inform the implementation of learning technologies by institutions and at the more local levels of subjects and courses.

In the first paper in this issue, Williams, Boyle, Molloy, Brightwell, Munro, Service, and Brown explore student attitudes to e-learning in undergraduate paramedic programmes from five universities, revealing student reluctance to engage in elearning that was not clearly related to their needs. This valuable finding can inform innovation in related programmes. Chen, Pedersen, and Murphy's thorough investigation of students' perceptions of information overload is based on quantity of information, quality of information and the medium interface through which the information is presented. The authors offer detailed recommendations for course design, and some of their findings are relevant to staff and students. Hepplestone, Holden, Irwin, Parkin and Thorpe review the literature on the use of technology in increasing student engagement with feedback, with recommendations on the use of online assessment and feedback tools and the need to uncover existing good practice. Smailes and Gannon-Leary consider virtual learning environments, social networking sites and virtual worlds as potential sites for a peer mentoring scheme, based on students' expressed desire for online peer mentoring and their current use of these three environments. These four papers have a strong emphasis on student practice, and can inform institutional innovation and what staff and students do, as long as the findings are communicated to them.

Benson, Anderson and Ooms' case study of staff attitudes to blended learning will be useful to organisations developing and implementing blended learning 
strategies. It is not enough to provide learning technologies: they have to be successfully embedded in staff and student practice. The implementation theme is developed further in the final paper where Buchan develops an Adaptive Cycle Framework in the context of learning technology introduction in an Australian university.

Our challenge in the Research in Learning Technology journal is to collect and disseminate this real-world knowledge to those who need it. We hope that reading these articles will encourage you to reflect on your practice and to have conversations with colleagues and students about how learning technology can be used most effectively in your own institution.

Frances Bell

Salford Business School, University of Salford, UK 